\title{
Multidisciplinary Discussion and Management of Rectal Cancer: A Population-based Study
}

\author{
H. A. M. Swellengrebel $\cdot$ E. G. Peters $\cdot$ A. Cats $\cdot$ O. Visser $\cdot$ \\ H. G. T. Blaauwgeers $\cdot$ V. J. Verwaal $\cdot$ M. L. van Velthuysen • \\ H. A. Cense - S. C. Bruin - C. A. M. Marijnen
}

Published online: 1 July 2011

(C) The Author(s) 2011. This article is published with open access at Springerlink.com

\begin{abstract}
Background The purpose of the present study was to evaluate the value of discussing rectal cancer patients in a multidisciplinary team (MDT).

Methods All treated rectal cancer patients (>T1M0) diagnosed in 2006-2008 were included. According to the national guidelines, neoadjuvant (chemo)radiotherapy should be given to all rectal cancer patients. Patients were scored as "discussed" (MDT+) only if documented proof was available. The primary endpoint was the number of positive circumferential resection margins (CRM $\leq 1 \mathrm{~mm})$. Results Of the 275 patients included, 210 were analyzed (exclusions: (recto)sigmoid tumor, acute laparotomy, and inoperability). Neoadjuvant treatment was applied in 174
\end{abstract}

This article was presented at the 15th Congress of the European Society of Surgical Oncology (ESSO) 2010 in Bordeaux, France, and at the European Multidisciplinary Colorectal Cancer Congress (EMCCC) 2010 in Nice, France.

H. A. M. Swellengrebel · E. G. Peters · A. Cats

Department of Gastroenterology, The Netherlands Cancer

Institute, Antoni van Leeuwenhoek Hospital, Plesmanlaan 121,

1066 CX Amsterdam, The Netherlands

e-mail: m.swellengrebel@nki.nl

O. Visser · H. G. T. Blaauwgeers

Comprehensive Cancer Centre Amsterdam, Post-box 9236, 1006

AE Amsterdam, The Netherlands

V. J. Verwaal

Department of Surgical Oncology, The Netherlands Cancer Institute, Antoni van Leeuwenhoek Hospital, Plesmanlaan 121, 1066 CX Amsterdam, The Netherlands

M. L. van Velthuysen

Department of Pathology, The Netherlands Cancer Institute, Antoni van Leeuwenhoek Hospital, Plesmanlaan 121, 1066 CX Amsterdam, The Netherlands
(83\%) patients and followed by total mesorectal excision in 171 (81\%) patients. Patients considered not to require downstaging, received short-course radiotherapy (SCRT) $(n=116)$ or no radiotherapy (no RT) $(n=36)$, whereas 58 more advanced patients received chemoradiotherapy (CRT). The MDT discussion took place in 116 cases $(55 \%)$. In the MDT + group an MRI was used more often $(p=0.001)$ and TNM staging was more complete $(p<0.001)$. The proportion of patients with advanced disease was higher in the MDT+ group $(88 \% \geq \mathrm{T} 3 / \mathrm{N}+$ versus $68 \% ; p=0.001)$. The overall CRM+ rate was $13 \%$ and did not differ between the MDT+ and the MDTgroup $(p=0.392)$. In patients receiving SCRT or no RT, the CRM+ rate was $10 \%$, whereas the rate was $20 \%$ for patients receiving CRT.

Conclusions Although no difference in CRM+ rate was found for those patients who were discussed and those who

\section{H. A. Cense}

Department of Surgery, Red Cross Hospital, Vondellaan 13, 1942 LE Beverwijk, The Netherlands

S. C. Bruin

Department of Surgery, Slotervaart Hospital,

Louwesweg 6, 1066 EC Amsterdam, The Netherlands

C. A. M. Marijnen

Department of Radiation Oncology, The Netherlands Cancer Institute, Antoni van Leeuwenhoek Hospital, Plesmanlaan 121, 1066 CX Amsterdam, The Netherlands

C. A. M. Marijnen ( $\square)$

Department of Clinical Oncology, Leiden University Medical Centre, Post-box 9600, 2300 RC Leiden, The Netherlands e-mail: C.A.M.Marijnen@lumc.nl 
were not, our results demonstrate room for improvement, especially in the selection of patients for SCRT or no RT. We advocate standardized documentation of treatment decisions and pathology reports.

\section{Introduction}

Over the last 10-15 years, the treatment of rectal cancer has evolved tremendously. Results of randomized controlled trials [1-3] have led to the introduction of "total mesorectal excision" (TME) [4] and preoperative (chemo)radiotherapy in Western Europe. Further research has established the role of the pathologist and radiologist in optimizing the multidisciplinary treatment of rectal cancer. Identification of tumor $\leq 1 \mathrm{~mm}$ from the circumferential resection margin $(\mathrm{CRM}+)$ has proved to be a strong predictor of local recurrence, distant metastases, and survival, resulting in a new surrogate endpoint of rectal cancer treatment [5-8]. Meanwhile, two radiological studies [9, 10] demonstrated that MRI can accurately predict involvement of this surgical CRM, thereby shifting the importance of an accurate T-stage on MRI to the more clinically appealing mesorectal fascia (MRF) at risk for a positive CRM after TME.

With regard to daily practice, the multimodality character and different treatment approaches have made the treatment of rectal cancer complex for health care professionals. An optimal patient-tailored decision-making process requires adequate interdisciplinary communication and coordination. Burton et al. have shown that a MRI directed multidisciplinary team (MDT) discussion of rectal cancer patients with implementation of a preoperative stratification significantly reduced the $\mathrm{CRM}+$ rate [11]. In certain patient groups, MDT discussion is increasingly becoming part of the standard of care, but evidence of its direct effect on the quality of cancer care remains limited [12]. Rectal cancer treatment guidelines for the Netherlands were introduced in 2004 and recommend that all patients be discussed by a MDT, irrespective of tumor stage or treatment plan. At the MDT meeting, patients are stratified according to risk of a positive CRM and subsequent local recurrence, and treated accordingly. Possible benefits of a more standardized approach to preoperative and histopathological staging are that certain parameters for quality assurance and possibilities for direct feedback to the MDT arise. For instance, patients receiving shortcourse radiotherapy (SCRT) or TME only should all have a negative CRM after TME, as otherwise chemoradiotherapy (CRT) would have been the preferred preoperative treatment to induce preoperative downstaging.

We studied surgical outcome after the introduction of TME with the administration of (chemo)radiotherapy in selected cases of rectal cancer in the greater Amsterdam region. The aim of this population-based study was to evaluate the additional value of discussing rectal cancer patients in a MDT, with the occurrence of a positive CRM as endpoint. Additional aims were to audit preoperative and histopathological staging and the implementation of preoperative risk stratification according to national guidelines.

\section{Patients and methods}

\section{Patients}

All patients diagnosed with cT2-4, N0-2 rectal cancer (TNM, 5th edition [13]) in one of six referring hospitals and one cancer referral center in the greater Amsterdam region, between January 2006 and January 2008, were included in the study. Exclusion criteria included patients with low risk cancer (cT1N0) who underwent local excision only, previous invasive cancers, a tumor located above the peritoneal deflection or more than $15 \mathrm{~cm}$ from the anal verge, or patients with metastasized disease.

\section{Data collection}

The Comprehensive Cancer Centre Amsterdam (CCCA) is an independent regional, population-based cancer registry with complete coverage of a population of approximately 3 million inhabitants. Following histopathological diagnosis, cancer patients are identified from the nationwide pathology registry (PALGA) and prospectively entered into the registry. This pathology registry also assures complete coverage of all patients diagnosed in the region, enabling a true population based study. Registration clerks routinely extract data on tumor stage, treatment, and follow-up from hospital and outpatient records. Additional information, not routinely collected, was collected retrospectively by the registration clerks of the CCCA or by one of the authors (either H.A.M.S. or E.G.P.) and included type of imaging for preoperative staging, discussion by a MDT, treatment decisions, and treatment outcome.

\section{MDT}

In the regional referral network of the cancer institute, patients are discussed in a multidisciplinary oncology meeting at the referring hospital. During an MDT discussion patient history, clinical and psychological condition, co-morbidity, modes of work-up, clinical staging, and optimal treatment strategies are discussed. The multidisciplinary team members present include a consulting oncologic surgeon, a radiation oncologist, and a medical 
oncologist (all from the cancer institute); the treating specialists (surgical oncologist, medical oncologist); and a radiologist, a pathologist, and a specialized nurse (nurse practitioner or case manager). If the MDT at the referring hospital decides to treat the patient with neoadjuvant radiotherapy, the patient is referred to the cancer institute. In case of doubt, when the optimal treatment approach is queried by the radiation oncologist at the cancer institute, or when a locally advanced tumor is suspected, the patient is also discussed in the cancer institute's specialized gastrointestinal cancer MDT.

Patients were scored as "discussed" (MDT+) only if documented proof was available that the patient had been discussed preoperatively at a MDT meeting, either in a referring institution or in the cancer institute.

\section{Treatment}

In the Netherlands, patients are stratified into three risk groups, each with a different treatment approach based on the risk of a positive CRM and subsequent local recurrence. Low-risk patients, defined as those with superficial tumors (T1N0) where treatment with local excision suffices, were excluded from the study. The intermediate risk group consists of patients with mobile resectable tumors (T2 and small T3, N0-1), suitable for treatment with preoperative $5 \times 5$ Gy radiotherapy (short-course radiotherapy; SCRT) followed directly by TME. In patients with small proximal tumors without clinical node metastasis, where the additional value of radiotherapy is under debate, preoperative SCRT may be withheld after discussion in a MDT. The high-risk group includes patients with locally advanced tumors, where the MRF and consequent surgical CRM is threatened or involved, or where extensive lymph node involvement is expected. In this group, the treatment of choice consists of preoperative downstaging with longcourse radiotherapy $(25 \times 2 \mathrm{~Gy})$ in combination with fluoropyrimidine-based chemotherapy [3, 14-16], followed by TME 6-8 weeks later. Standard chemotherapy in the study period was capecitabine, $825 \mathrm{mg} / \mathrm{m}^{2}$ twice daily on days $1-33$. In three patients, bevacizumab $(5 \mathrm{mg} / \mathrm{kg}$ IV on days $-14,1,15$, and 29) was added in trial setting. Four patients received 50 Gy only because chemotherapy was contraindicated.

\section{Pathology}

An involved CRM (CRM+) was defined as tumor or an involved lymph node $\leq 1 \mathrm{~mm}$ from the CRM. If the CRM was not mentioned in the report $(n=81)$, additional investigation of the CRM was performed by a pathologist (M.L.V.).
Statistical analysis

Data were entered into a database and analyzed with the Statistical Package for the Social Sciences (version 15.0 for Windows; SPSS, Chicago, IL). To determine significance in differences between groups of patients, chi-square tests were used for categorical variables unless stated otherwise, whereas the $t$-test and the Mann-Whitney $U$-test were used for continuous variables. A $p$ value of $<0.05$ (two-sided) was regarded statistically significant.

\section{Results}

Initially, 275 patients with intermediate or high-risk rectal cancer were identified. Patients whose tumors were inoperable $(n=24)$, patients undergoing non-elective surgery $(n=1)$, and those with a (recto)sigmoid tumor $(n=40)$ were excluded, leaving 210 patients suitable for analysis. Fifty-five percent (116/210) of all patients were discussed by a MDT. In Table 1, baseline patient and treatment characteristics are shown for all patients, and also for MDT + and MDT - groups. Of the discussed patients, 50\% were discussed at the referring hospital only, $20 \%$ were discussed both at the referring hospital and at the cancer institute, and $30 \%$ were discussed at the cancer institute only.

\section{Staging}

Of the 210 patients, $178(85 \%)$ had a clinical TNM stage reported, including both a $\mathrm{T}$ stage and an $\mathrm{N}$ stage. In the MDT + group, staging was more complete (94\% versus 73\%; $p<0.001)$, and a MRI study was also performed more often $(p=0.001)$. In addition, the proportion of patients with advanced disease ( $\geq \mathrm{T} 3$ and/or $\mathrm{N}+$ ) was higher $(p=0.001)$ in the MDT + group. Correlation of the clinical and pathological $\mathrm{T}$ and $\mathrm{N}$ stages of the subgroup of patients receiving SCRT or TME only (to exclude downstaging effects of CRT) revealed a staging accuracy for $\mathrm{T}$ stage of $57 \%$ (Table 2) and $\mathrm{N}$ stage of $63 \%$. In Table 2 only patients with complete cT and $\mathrm{pT}$ are included. No significant difference in tumor or nodal staging accuracy (understaging, accurate, overstaging) was found between the MDT + and MDT - groups ( $p=0.139$ and 0.902).

\section{Treatment}

Preoperative (chemo)radiotherapy was employed in 174 (83\%) patients. Three patients did not proceed to surgery due to death during CRT, poor performance status, and local progression, respectively. Thirty-six patients underwent TME only. Patients receiving preoperative 
Table 1 Patient and treatment characteristics according to discussion by a MDT
$S C R T$ short course radiotherapy, $C R T$ chemoradiotherapy, $L A R$ low anterior resection, $A P R$ abdominoperineal resection, $P t$ patients

${ }^{\text {a }}$ Percentages are column percentages unless stated otherwise and are rounded off

b Percentage is of the total number of patients

c Binomial test

${ }^{d}$ Linear-by-linear association

e (Chemo)radiotherapy versus no radiotherapy

${ }^{f}$ APR versus sphincter sparing surgery

\begin{tabular}{|c|c|c|c|c|c|c|c|}
\hline & \multicolumn{2}{|l|}{ Total } & \multicolumn{2}{|l|}{ MDT+ } & \multicolumn{2}{|l|}{ MDT- } & \multirow[t]{2}{*}{$p$ value } \\
\hline & Number & $\%^{a}$ & Number & $\%^{\mathrm{a}}$ & Number & $\%^{\mathrm{a}}$ & \\
\hline Total patients & 210 & 100 & 116 & $55^{\mathrm{b}}$ & 94 & $45^{\mathrm{b}}$ & $0.147^{\mathrm{c}}$ \\
\hline \multicolumn{8}{|l|}{ Sex } \\
\hline Male & 122 & 58 & 63 & 54 & 59 & 63 & \multirow[t]{2}{*}{0.217} \\
\hline Female & 88 & 42 & 53 & 46 & 35 & 37 & \\
\hline \multicolumn{8}{|l|}{ Age } \\
\hline Median & 70 & & 69 & & 70 & & \multirow[t]{2}{*}{0.312} \\
\hline Range & $37-89$ & & $37-87$ & & $41-89$ & & \\
\hline \multicolumn{8}{|l|}{ Tumor location } \\
\hline $0-5 \mathrm{~cm}$ & 75 & 36 & 52 & 45 & 23 & 24 & \multirow[t]{4}{*}{0.002} \\
\hline $6-10$ & 89 & 42 & 46 & 40 & 43 & 46 & \\
\hline$>10$ & 45 & 21 & 17 & 15 & 28 & 30 & \\
\hline Unknown & 1 & 1 & 1 & 1 & 0 & 0 & \\
\hline \multicolumn{8}{|l|}{ MRI } \\
\hline Yes & 175 & 83 & 106 & 91 & 69 & 73 & \multirow[t]{2}{*}{0.001} \\
\hline No & 35 & 17 & 10 & 9 & 25 & 27 & \\
\hline
\end{tabular}

Clinical tumor stage (cT)

$\begin{array}{llll}1 & 6 & 3 & 2\end{array}$

$\begin{array}{llll}2 & 47 & 22 & 20\end{array}$

$\begin{array}{llll}3 & 103 & 49 & 67\end{array}$

$\begin{array}{llll}4 & 30 & 14 & 25\end{array}$

Unknown 24

112

Clinical node stage $(\mathrm{cN})$

$\begin{array}{ll}0 & 108\end{array}$

$1 \quad 69$

$2 \quad 17$

$\begin{array}{lll} & 51 & 55\end{array}$

Unknown

17

$17-8$

Advanced stage $(\geq \mathrm{T} 3$ or $\mathrm{N}+$ ) $n=198$

$\begin{array}{lll}\text { Yes } & 149 & 81 \\ \text { No } & 36 & 20\end{array}$

Type of preoperative treatment

$\begin{array}{llllrrrr}\text { None } & 36 & 17 & 7 & 6 & 29 & 31 & <0.001^{\mathrm{e}} \\ \text { SCRT } & 116 & 55 & 61 & 53 & 55 & 59 & \\ \text { CRT } & 58 & 27 & 48 & 41 & 10 & 11\end{array}$

Type of surgery

$\begin{array}{llclclrl}\text { LAR } & 115 & 55 & 48 & 41 & 67 & 71 & <0.001^{\mathrm{f}} \\ \text { Hartmann } & 28 & 13 & 20 & 17 & 8 & 9 & \\ \text { APR } & 64 & 31 & 46 & 40 & 18 & 19 & \\ \text { No surgery } & 3 & 1 & 2 & 2 & 1 & 1\end{array}$

Histopathological tumor stage (pT) $n=207$

\begin{tabular}{llrlrlrl}
0 & 9 & 4 & 8 & 7 & 1 & 1 & $0.262^{\mathrm{d}}$ \\
1 & 20 & 10 & 11 & 10 & 9 & 10 & \\
2 & 68 & 32 & 35 & 31 & 33 & 35 & \\
3 & 102 & 49 & 56 & 49 & 46 & 49 & \\
4 & 8 & 4 & 4 & 4 & 4 & 4 & \\
\multicolumn{2}{l}{ Histopathological nodal stage $(\mathrm{pN})$} & $n=207$ & & & & & \\
0 & 130 & 63 & 73 & 64 & 57 & 61 & $0.437^{\mathrm{b}}$ \\
1 & 50 & 24 & 26 & 23 & 24 & 26 & \\
2 & 26 & 13 & 15 & 13 & 11 & 12 & \\
Unknown & 1 & 0 & 0 & 0 & 1 & 1 & \\
\hline
\end{tabular}


Table 2 Correlation of the clinical and pathological $\mathrm{T}$ stages of the subgroup of patients not receiving CRT

\begin{tabular}{lrrrrr}
\hline & $\mathrm{pT}$ & & & & Total \\
\cline { 2 - 5 } $\mathrm{cT}$ & 1 & 2 & 3 & 4 & \\
\hline 1 & 3 & 3 & 0 & 0 & 6 \\
2 & 10 & 22 & 10 & 1 & 43 \\
3 & 3 & 22 & 45 & 2 & 72 \\
4 & 0 & 1 & 2 & 1 & 4 \\
Total & 16 & 48 & 57 & 4 & 125 \\
\hline
\end{tabular}

(chemo)radiotherapy were discussed more often by a MDT than those undergoing TME only (63\% versus 19\%; $p<0.001)$. Furthermore, patients with distal tumors ( $\leq 5 \mathrm{~cm}$ from the anal verge) were more likely to be discussed in a MDT than those with more proximal $(6-15 \mathrm{~cm})$ tumors $(69 \%$ versus $47 \%$ MDT $+; p=0.002)$.

\section{Outcome}

The CRM was initially reported in $126(61 \%)$ and additionally measured in $71(34 \%)$ of the 207 resected patients, whereas in 10 patients the CRM remained unknown. In total, in 24 patients a positive CRM was documented after resection, while in one patient the tumor was irresectable after CRT, resulting in an overall CRM+ rate of $13 \%$ (25/ 198). An APR was not associated with significantly more $\mathrm{CRM}+$ resections (18\% versus $10 \%$ after sphincter-saving resections; $p=0.093$ ). Increasing pathological $\mathrm{T}$ - and $\mathrm{N}$-stage were both associated with increasing CRM+ rates ( $p \leq 0.001$ and $p=0.001$, respectively).

The flow diagram in Fig. 1 illustrates outcome after different treatment strategies. The $\mathrm{CRM}+$ rate for intermediate risk patients (i.e., those receiving SCRT or no RT) was $10 \%(14 / 143)$ while it was $20 \%(11 / 55)$ after CRT (including one irresectable patient). Furthermore, in the intermediate risk subgroup, distal tumors were associated with more $\mathrm{CRM}+$ resections $(8 / 38 \mathrm{CRM}+; p=0.011)$ compared to those located $6-15 \mathrm{~cm}$ from the anal verge (6/ $105 \mathrm{CRM}+$ ).

Table 3 shows CRM involvement according to MDT discussion. The overall CRM+ rate did not differ significantly between the MDT+ group $(14 \%, 16 / 111)$ and the MDT - group $(10 \%, 9 / 87)(p=0.392)$, even when patients with a positive CRM determined by an involved node were excluded from the comparison $(p=0.198)$. When analyzing the subgroup of intermediate risk patients (receiving SCRT or no RT) only, the CRM+ rate remained similar ( $12 \%$ versus $8 \%$, respectively; $p=0.385)$. The root-cause analysis in Table 4 describes the characteristics and
Fig. 1 Flow diagram of treatment and $\mathrm{CRM}+$ rate
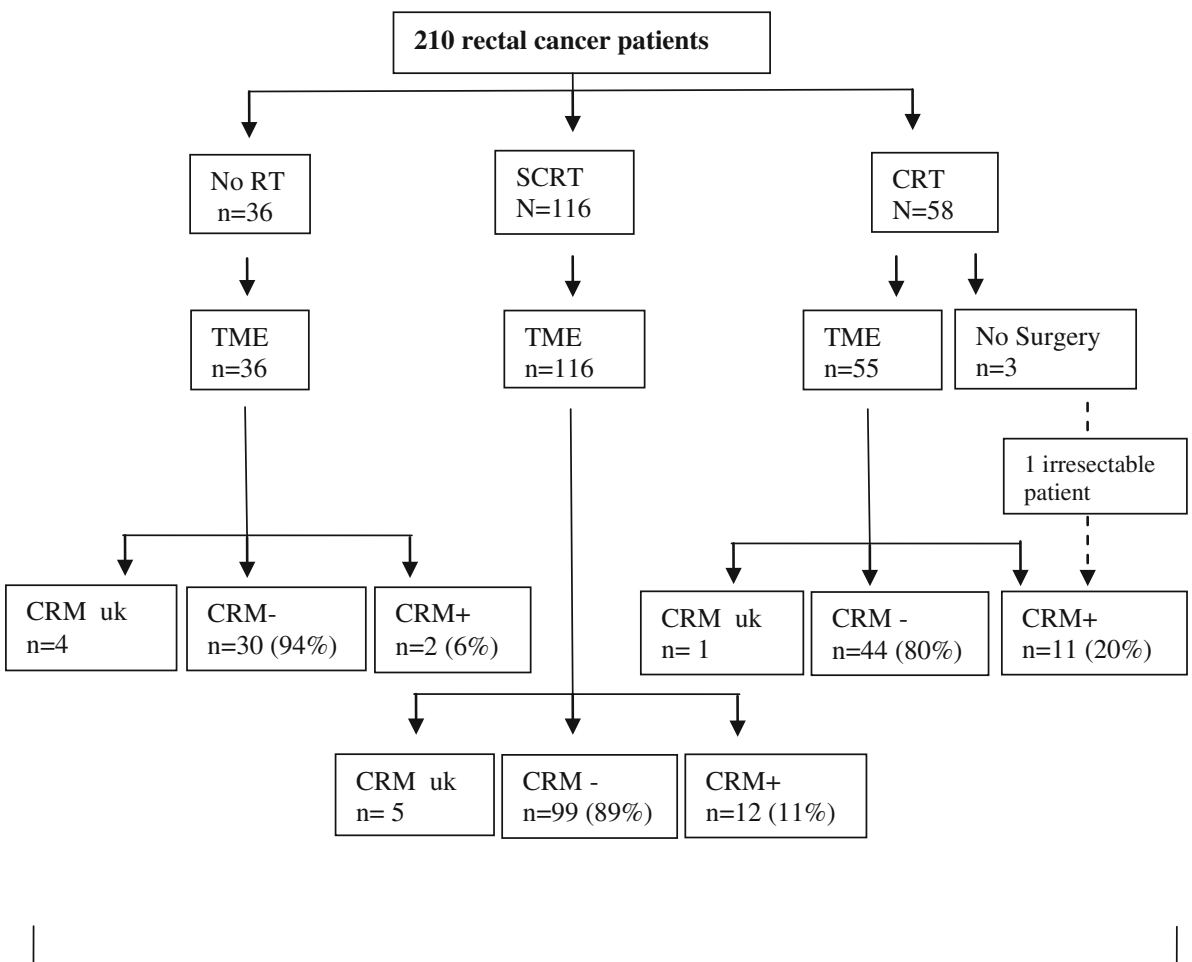

Overall CRM+ = $13 \%(25 / 198)$ 
Table 3 CRM involvement according to MDT discussion

\begin{tabular}{|c|c|c|c|c|c|c|c|c|c|}
\hline \multirow[b]{2}{*}{$\begin{array}{l}\text { Preoperative } \\
\text { treatment }\end{array}$} & \multicolumn{4}{|c|}{$\mathrm{MDT}+(\%)(n=114)$} & \multicolumn{4}{|c|}{ MDT- $(\%)(n=94)$} & \multirow[t]{2}{*}{ Total } \\
\hline & $\begin{array}{l}\text { CRM } \\
>1 \mathrm{~mm}\end{array}$ & $\begin{array}{l}\text { Primary tumor } \\
\leq 1 \mathrm{~mm}\end{array}$ & $\begin{array}{l}\text { Positive node } \\
\leq 1 \mathrm{~mm}\end{array}$ & uk & $\begin{array}{l}\text { CRM } \\
>1 \mathrm{~mm}\end{array}$ & $\begin{array}{l}\text { Primary tumor } \\
\leq 1 \mathrm{~mm}\end{array}$ & $\begin{array}{l}\text { Positive node } \\
\leq 1 \mathrm{~mm}\end{array}$ & uk & \\
\hline None & $6(100)$ & 0 & 0 & 1 & $24(92)$ & $1(4)$ & $1(4)$ & 3 & 36 \\
\hline SCRT & $52(87)$ & $7(12)$ & $1(2)$ & 1 & $47(92)$ & $3(6)$ & $1(2)$ & 4 & 116 \\
\hline CRT & $37(82)$ & $7(16)$ & $1(2)$ & 1 & 7 (70) & $2^{\mathrm{a}}(20)$ & $1(10)$ & 0 & 56 \\
\hline Total & $95(86)$ & $14(13)$ & $2(2)$ & 3 & $78(90)$ & $6(7)$ & $3(3)$ & 7 & $208^{\mathrm{a}}$ \\
\hline
\end{tabular}

$M D T+$ discussed by a multidisciplinary team, $M D T-$ not discussed, CRM circumferential resection margin, CRT chemoradiotherapy, SCRT short-course radiotherapy, $u k$ unknown

${ }^{\text {a }}$ Including 1 irresectable tumor

Table 4 CRM-positive patients: a root-cause analysis

\begin{tabular}{|c|c|c|c|c|c|c|c|c|}
\hline $\begin{array}{l}\text { Patient } \\
\text { number }\end{array}$ & $\begin{array}{l}\text { Height of } \\
\text { tumor, cm }\end{array}$ & $\begin{array}{l}\text { MDT+I- } \\
\text { and } \\
\text { location }\end{array}$ & MRI & $\begin{array}{l}\text { Preoperative } \\
\text { therapy }\end{array}$ & $\begin{array}{l}\text { Operative } \\
\text { procedure }\end{array}$ & $\begin{array}{l}\text { CRM, } \\
\mathrm{mm}\end{array}$ & $\begin{array}{l}\text { Tumour or } \\
\text { node at } \\
\text { CRM }\end{array}$ & $\begin{array}{l}\mathrm{TN} \\
\text { stage }\end{array}$ \\
\hline 1 & $0-5$ & - & No & None & Hartmann & 0 & Tumor & $\begin{array}{l}\text { cT4Nx } \\
\text { pT4N0 }\end{array}$ \\
\hline 2 & $0-5$ & - & Yes & SCRT & LAR & 0 & Lymph node & $\begin{array}{l}\text { cT3N1 } \\
\text { pT3N1 }\end{array}$ \\
\hline 3 & $0-5$ & - & Yes & SCRT & LAR & $\leq 1$ & Tumor & $\begin{array}{l}\text { cT3N1 } \\
\text { pT3N0 }\end{array}$ \\
\hline 4 & $0-5$ & $\begin{array}{r}\text { Referring } \\
\text { hospital }\end{array}$ & Yes & SCRT & Hartmann & $\leq 1$ & Tumor & $\begin{array}{l}\text { cT3N0 } \\
\text { pT3N2 }\end{array}$ \\
\hline 5 & $0-5$ & $\begin{array}{r}\text { Referring } \\
\text { hospital }\end{array}$ & Yes & SCRT & APR & $\leq 1$ & Tumor & $\begin{array}{l}\text { cT2N0 } \\
\text { pT3N0 }\end{array}$ \\
\hline 6 & $0-5$ & $\begin{array}{r}\text { Referring } \\
\text { hospital }\end{array}$ & Yes & SCRT & APR & $\leq 1$ & Tumor & $\begin{array}{l}\text { cT2N1 } \\
\text { pT2N0 }\end{array}$ \\
\hline 7 & $0-5$ & $\begin{array}{r}\text { Referring } \\
\text { hospital }\end{array}$ & Yes & SCRT & APR & 0 & Tumor & $\begin{array}{l}\text { cT3N1 } \\
\text { pT2N2 }\end{array}$ \\
\hline 8 & $0-5$ & $\begin{array}{l}\text { Cancer } \\
\text { Institute }\end{array}$ & Yes & SCRT & APR & $\leq 1$ & Lymph node & $\begin{array}{l}\text { cT2N2 } \\
\text { pT2N2 }\end{array}$ \\
\hline 9 & $6-10$ & - & Yes & SCRT & LAR & 0 & Tumor & $\begin{array}{l}\text { cT2N0 } \\
\text { pT4N2 }\end{array}$ \\
\hline 10 & $6-10$ & - & Yes & SCRT & APR & 0 & Tumor & $\begin{array}{l}\text { cT3N1 } \\
\text { pT4N0 }\end{array}$ \\
\hline 11 & $6-10$ & $\begin{array}{r}\text { Referring } \\
\text { hospital }\end{array}$ & Yes & SCRT & LAR & 0 & Tumor & $\begin{array}{l}\text { cT3N1 } \\
\text { pT3N1 }\end{array}$ \\
\hline 12 & $6-10$ & Both & Yes & SCRT & LAR & 0 & Tumor & $\begin{array}{l}\text { cT3N0 } \\
\text { pT3N1 }\end{array}$ \\
\hline 13 & $>10$ & - & No & None & LAR & $\leq 1$ & Lymph node & $\begin{array}{l}\text { cTxN0 } \\
\text { pT3N1 }\end{array}$ \\
\hline 14 & $>10$ & $\begin{array}{l}\text { Cancer } \\
\text { Institute }\end{array}$ & Yes & SCRT & Hartmann & $\leq 1$ & Tumor & $\begin{array}{l}\text { cT3N0 } \\
\text { pT3N1 }\end{array}$ \\
\hline
\end{tabular}

No information on the completeness of the surgical specimen was available $M D T$ multidisciplinary team

\section{6} 6 (n) 徆 


\section{Discussion}

This population-based study represents daily practice in the Netherlands in the era following the TME trial. Only half of the patients diagnosed with rectal cancer in our region are discussed by a MDT. As predominantly advanced patients were selected for discussion, this may have influenced the study outcome whereby no significant benefit was found for MDT discussion on the CRM+ rate. We found an overall CRM+ rate of $13 \%$, while for the subgroup of patients in which preoperative downstaging was not deemed necessary, the rate was $10 \%$. Documenting the CRM in the pathology report has not yet become a feature of the standard of care, as initially it was documented in only $61 \%$ of patients.

$\mathrm{CRM}+$ rates in the literature

In the TME trial, patients with resectable rectal cancer were randomized between TME alone and SCRT followed by TME within 10 days. In this quality-controlled study undertaken in the era preceding the use of MRI, the reported $\mathrm{CRM}+$ rates after macroscopic complete resection were $18 \%$ and $16 \%$, respectively [17]. The CRM rate of $10 \%$ in patients receiving SCRT or TME only in our study reflects progression in this field; but it also illustrates room for further improvement in patient selection, especially in patients receiving SCRT $(11 \% \mathrm{CRM}+)$. In the MRC CR07 study, a study comparable to the TME trial, the $\mathrm{CRM}+$ rates were $10 \%$ of those undergoing a macroscopic complete resection in the SCRT arm and $12 \%$ in the TME alone arm [2]. During this study period the MRI was being introduced as selection tool, with $41 \%$ of patients staged with MRI, indicating the advantages of MRI in patient selection.

\section{Effect of the MDT discussion}

Dutch rectal cancer treatment guidelines recommend discussing all patients in a MDT meeting. As mentioned above, our study shows that this is not yet the case in our region.

Despite the fact that recording the results of the MDT discussion is mandatory in the Netherlands, it is possible that we underestimated the number of patients discussed because there was a lack of documentation. The use of a pro forma for all patients would facilitate more complete documentation of the discussion or the reason why a patient was not discussed. Burton et al. [11] evaluated the effects of regional implementation of a MDT discussion and reported a CRM+ rate of $13 \%$, which is equal to ours. In contrast to our study, they showed that discussion by a MDT was associated with a significantly lower $\mathrm{CRM}+$ rate
(26\% versus $8 \%)$. At re-audit one year later, after introduction of compulsory MDT discussion for all rectal cancer patients, $96 \%$ were discussed and the CRM+ rate was decreased to $7 \%$ overall, which emphasizes the importance and effect of multidisciplinary interaction in their region. Due to a selection of advanced patients for discussion a true comparison between MDT+ and MDT - patients in our series is difficult, especially because advanced patients have a higher a priori risk of a CRM+ resection, thereby undermining the value of the MDT. Although acceptable $\mathrm{CRM}+$ rates were obtained with this selective discussion approach, there is room for improvement. In fact, six $\mathrm{CRM}+$ patients, who were not discussed and received SCRT or no RT, might have benefitted from a discussion by a MDT. This is underscored by the fact that three of these patients had a pT4 tumor, indicating that CRT was absolutely necessary. We therefore advocate discussion of all rectal cancer patients in a MDT.

Regarding the MDT itself, eight patients discussed in a MDT received SCRT but ended up with a positive CRM, indicating that the MDT itself also needs improvement. However, another confounding factor may be the quality of the surgical specimen (Table 4).

\section{Pre-treatment staging}

With regard to preoperative staging, T-staging accuracy with MRI was $57 \%$, similar to that of the MERCURY group in their national MRI implementation program (53\%) [18]. Inaccuracy in distinguishing T1 from a T2 (34\% in our study) and T2 from a T3 $(32 \%)$ reported in this study is in line with the literature and indicates that MRI does have its limits in $\mathrm{T}$ and $\mathrm{N}$ staging [9]. However, recent studies $[9,10]$ have shown that a shift in staging has taken place from primarily an accurate T-stage on MRI to a more clinically important mesorectal fascia (MRF) at risk for a positive CRM after TME. In our study, treatment stratification was based on the risk of a positive CRM $(<2 \mathrm{~mm}$ at risk), but exact distances to the MRF on MRI were not documented. Twelve of the 14 patients with a positive CRM after SCRT or TME only were staged with MRI, indicating that more attention is needed to accurately select patients at risk. A pro forma with standardized quantification of margins, tumor infiltration depth, and size and aspects of nodes might facilitate further optimization of staging. Furthermore, a MRI-based MDT discussion will lead to a better understanding of the anatomy of the rectal tumor, which is important for all specialists involved.

Post-chemoradiotherapy re-staging

In the 11 patients with a positive resection margin after CRT, a complete resection was not possible, indicating that 
sufficient downstaging after chemoradiotherapy is not always achieved. Re-staging after chemoradiotherapy, which was not the standard of care during this study period, might have optimized treatment by enabling the surgeon to plan the resection according to the (lack of) response or to even to decide to delay surgery to optimize response. However, on MRI microscopic tumor deposits remain difficult to distinguish from a benign desmoplastic reaction. Possibly, positron emission tomographic (PET) scanning would aid the identification of vital and metabolically active tumor cells. Other possibilities to further decrease the CRM+ rate after CRT include centralization of the treatment and further optimization of the synergistic effect of chemoradiotherapy on tumor downstaging with either intensified chemoradiotherapy or tumor-specific biologicals, like vascular endothelial growth factor (VEGF) inhibitors. However, whether this approach will really lead to better clinical outcome remains to be seen. In the ACCORD 12 trial [19], T3-4M0 rectal cancer patients were randomized between 45 Gy RT with capecitabine or 50 Gy RT with capecitabine and oxaliplatin. A significant decrease in CRM+ resections with intensified CRT (19\% versus $10 \% ; p=0.02$ ) was observed. Whether this was due to the increased radiotherapy dose or the addition of oxaliplatin remains speculative.

\section{Study limitations}

Because of the retrospective population-based nature of this study; some limitations need to be addressed. We only scored patients as MDT+ if documented proof was available that the patient had been discussed preoperatively at a MDT meeting. It is possible that the number of patients discussed by a MDT has been underreported. Exact details on treatment decisions and reasons underlying them-for instance: patient unfit for chemo(radiotherapy)—were not available. Regarding patient outcome, follow-up was not long enough to demonstrate the prognostic importance of a positive CRM with regard to the (local) recurrence rate or overall survival.

\section{Conclusions}

In conclusion, in our region MRI-based preoperative stratification has led to a selective approach to MDT, with $55 \%$ of patients being discussed. Even though national guidelines state that all patients should be discussed in a MDT before treatment is begun, this is not yet the case in clinical practice. Interestingly, even though the group of patients discussed consisted of those with higher risk for a positive CRM because of their advanced stage of disease, this did not result in more CRM positivity in comparison to the group of patients not discussed by a MDT, most of whom had less advanced disease. In this latter group one would expect fewer positive CRM resections. The CRM+ rate of $10 \%$ in patients not receiving CRT indicates room for improvement. The message of this study is clear: the implementation of MRI in optimizing patient selection has not yet reached its full potential. Standardized staging (MRI and histopathology) in all rectal cancer patients will lead to improvement of rectal cancer treatment and create opportunities for feedback to the MDT.

Acknowledgments The authors acknowledge the contribution to data collection made by the registration clerks of the Comprehensive Cancer Centre Amsterdam and also thank all involved colorectal surgeons of the Sint Lucas Andreas Hospital in Amsterdam, the Tergooi Hospital in Hilversum and Blaricum, and the Spaarne Hospital in Hoofddorp, for their collaboration.

Open Access This article is distributed under the terms of the Creative Commons Attribution Noncommercial License which permits any noncommercial use, distribution, and reproduction in any medium, provided the original author(s) and source are credited.

\section{References}

1. Kapiteijn E, Marijnen CA, Nagtegaal ID et al (2001) Preoperative radiotherapy combined with total mesorectal excision for resectable rectal cancer. N Engl J Med 345:638-646

2. Sebag-Montefiore D, Stephens RJ, Steele R et al (2009) Preoperative radiotherapy versus selective postoperative chemoradiotherapy in patients with rectal cancer (MRC CR07 and NCIC-CTG C016): a multicentre, randomised trial. Lancet 373(9666):811-820

3. Sauer R, Becker H, Hohenberger W et al (2004) Preoperative versus postoperative chemoradiotherapy for rectal cancer. N Engl J Med 351:1731-1740

4. Heald RJ, Ryall RD (1986) Recurrence and survival after total mesorectal excision for rectal cancer. Lancet 1(8496):1479-1482

5. Quirke P, Dixon MF (1988) The prediction of local recurrence in rectal adenocarcinoma by histopathological examination. Int $\mathbf{J}$ Colorectal Dis 3:127-131

6. Quirke P, Steele R, Monson J et al (2009) Effect of the plane of surgery achieved on local recurrence in patients with operable rectal cancer: a prospective study using data from the MRC CR07 and NCIC-CTG CO16 randomised clinical trial. Lancet 373(9666):821-828

7. Birbeck KF, Macklin CP, Tiffin NJ et al (2002) Rates of circumferential resection margin involvement vary between surgeons and predict outcomes in rectal cancer surgery. Ann Surg 235:449-457

8. Nagtegaal ID, Quirke P (2008) What is the role for the circumferential margin in the modern treatment of rectal cancer? J Clin Oncol 26:303-312

9. Beets-Tan RG, Beets GL, Vliegen RF et al (2001) Accuracy of magnetic resonance imaging in prediction of tumour-free resection margin in rectal cancer surgery. Lancet 357(9255):497-504

10. Brown G, Radcliffe AG, Newcombe RG et al (2003) Preoperative assessment of prognostic factors in rectal cancer using high-resolution magnetic resonance imaging. Br J Surg 90:355-364

11. Burton S, Brown G, Daniels IR et al (2006) MRI directed multidisciplinary team preoperative treatment strategy: the way to 
eliminate positive circumferential margins? $\mathrm{Br} \mathrm{J}$ Cancer 94:351-357

12. Fleissig A, Jenkins V, Catt $S$ et al (2006) Multidisciplinary teams in cancer care: are they effective in the UK? Lancet Oncol 7:935-943

13. International Union Against Cancer (1997) TNM classification of malignant tumors, 5th edn. Wiley, New York, pp 66-69

14. Bosset JF, Collette L, Calais G et al (2006) Chemotherapy with preoperative radiotherapy in rectal cancer. $\mathrm{N}$ Engl $\mathrm{J}$ Med 355:1114-1123

15. Braendengen M, Tveit KM, Berglund A et al (2008) Randomized phase III study comparing preoperative radiotherapy with chemoradiotherapy in nonresectable rectal cancer. J Clin Oncol 26:3687-3694

16. Gerard JP, Conroy T, Bonnetain F et al (2006) Preoperative radiotherapy with or without concurrent fluorouracil and leucovorin in T3-4 rectal cancers: results of FFCD 9203. J Clin Oncol 24:4620-4625

17. Marijnen CA, Nagtegaal ID, Kapiteijn E et al (2003) Radiotherapy does not compensate for positive resection margins in rectal cancer patients: report of a multicenter randomized trial. Int J Radiat Oncol Biol Phys 55:1311-1320

18. Magnetic Resonance Imaging Rectal Cancer European Equivalence (MERCURY) Study (2007) Extramural depth of tumor invasion at thin-section MR in patients with rectal cancer: results of the MERCURY study. Radiology 243:132-139

19. Gerard JP, Azria D, Gourgou-Bourgade S et al (2010) Comparison of two neoadjuvant chemoradiotherapy regimens for locally advanced rectal cancer: results of the phase III trial ACCORD 12/0405-Prodige 2. J Clin Oncol 28:1638-1644 